\title{
Selective Estrogen Receptor Modulator CC-8490
}

National Cancer Institute

\section{Source}

National Cancer Institute. Selective Estrogen Receptor Modulator CC-8490. NCI

Thesaurus. Code C38711.

A benzopyran with potential antineoplastic activity. CC-8490 acts as a selective estrogen receptor modulator (SERM), inhibiting the proliferation of estrogen-sensitive breast cancer cells. This agent also inhibits growth and induces apoptosis of glioblastoma cells via a mechanism independent of estrogen receptor-related mechanisms. ( $\mathrm{NCl04)}$ 